\title{
PBL for Doctoral Students in Collaboration with SMEs: "Thinking like a Professional Engineer"
}

\author{
P. Kapranos \\ Department of Materials Science \& Engineering, The University of Sheffield, Sheffield, UK \\ Email: kapranos@sheffield.ac.uk
}

Received May 2015

\begin{abstract}
The recent global economic downturn brought sharply into focus the need for engineers that excel not only technically and academically but also having a multiplicity of transferable skills, flexibility of mind and resilience. Considerable effort has been focused in UK and internationally on the development of doctoral students with such mind-sets and skills. At the Universities of Sheffield \& Manchester, the teaching of transferrable skills in the Doctoral Training Centre for Advanced Metallics is done in the form of a Diploma in Personal \& Professional Skills and such skills are embedded in the students' consciousness by practice. The development of Problem Based Learning experience through a two week long exercise where groups of students tackle "real-life" problems at an SME has been organized and successfully taken place over the past two years and students, staff and industrial partners have all felt the benefits. This work shows the multiplying effect that the SME case studies have on student skill and attitude development and as a result their employability. Colleagues will see how the use of "real-life" problem solving can be used to focus and sharpen the students' use of transferrable skills that have been taught in other parts of a structured course. The reality of the situation faced, the tight time limits afforded, the responsibility to function and deliver as part of a group of "professional" consultants act as multipliers of the skills employed towards generating and proposing solutions. Students see in practice what transferrable skills mean to them and of course employers are suitably impressed when they see skills they seek from graduates being used to the full.
\end{abstract}

\section{Keywords}

PBL (Problem Based Learning), Transferrable Skills, Doctoral Level, Professional Skills

\section{Introduction}

I firmly believe that traditional methods of educating our students are not adequate to cope with their world of vast technological changes at ever increasing rates of change, proliferation of information, the need for multidisciplinary approaches, market Globalization and the Cultural awareness that it implies, Environmental issues and 
social responsibility, new business structures emerging, rapid change of knowledge, to name just a few of the challenges facing them.

Relating the above to my particular field of engineering instruction, I believe that although delivery of technical knowledge and understanding of the basic relevant concepts to our students are absolutely necessary, on their own they are not enough to help them fulfil their future careers, unless they are given the skills on how to manage, apply and use this knowledge in "real-life" situations. In other words, instead of delivering technically competent engineering graduates, we must develop the "full professionals" of tomorrow; persons with the technical know-how, skills to use it and the right attitudes that will allow them to practice these skills in their working environments. Knowledge is the "data base" of the professional engineer; skills are the tools used to manipulate the knowledge in order to meet goals that are strongly influenced by attitudes. In addition, engineers either directly or indirectly "produce our physical" world; they make the stuff that make our lives better, easier, more fulfilling and therefore since they make "stuff" they must also become familiar with the business side of what is done with this "stuff"; how it is marketed, how it is sold, who are the customers, who drives development, how do the products they design get from design idea to the market place, how the operation is financed, how products are costed, etc.

The above implies not only the need for a changing curriculum but also the need to train the educators who typically stumble into teaching through their research with hardly any educational training and deciding in turn to teach the way they had been taught, by lecturing, which is quite an effective way for transferring information. However, when you try to build skills, or change attitudes and behavior, lecturing is no longer the best way forward; tacit knowledge can be transmitted through instruction, not by the book. Of course, there are a number of pedagogical approaches that have been developed over the years such as team based learning, problem based learning, action and experiential learning, peer learning, to name a few; all part and parcel of enterprise education as more fully outlined by Colin Jones [1] in his paper on "Enterprise education: revisiting Whitehead to satisfy Gibbs".

In the case of the part of the New Doctoral Training Centre for Advanced Metallics Diploma in personal \& Professional Skills, clear Aims and Objectives were set, assessment that was aligned with these objectives, feedback, multi-based learning, student based learning, action learning, peer learning, continuous assessments, personal portfolios, mini-research projects, public engagement projects, a Science \& Engineering in the Media intensive 3 day course, and other pedagogical tools came into play, were tried and through iteration the Diploma developed since its conception to a flexible training product that can adjust itself as we are progressing. Although the aims and objectives are clearly set out to be educationally sound and compatible with the award of the Diploma, we have inserted enough flexibility in the ways we are to achieve them and the ways we can assess and verify that they are being achieved, to the satisfaction of our external assessor.

Z. Bauman [2] likens the delivery of education to an intelligent missile. He states that ballistic missiles are ideal for positional warfare, i.e. when the targets do not move, but when the targets are invisible to the gunner, faster than missiles, erratic, unpredictable, then one needs an intelligent missile that constantly updates and corrects its position and trajectory and even chose its target as it goes. This relates well to my flexible curriculum concept that relates to the fact that students learn as they go but also should have the ability to forget or change their minds about what they are learning and shape their learning to new contexts and circumstances; information "ages" rapidly and knowledge is disposable and if no longer needed can be thrown away, forgotten or replaced.

Surprising unexpected things lead to great discoveries; new things are not found by walking along a precisely defined path, things just happen and the key is their connection to the existing whole by the inquisitive, prepared, fertile and flexible mind of an observer that does not hinder his/hers imagination. It is the ability to discern the opportunities, disassemble, re-arrange them and create something new that we are trying to nurture in our students. This is what we believe means to be enterprising; it's a way of life.

We see the Diploma as an educational experiment; a paradigm shift from the traditional engineering modes of teaching and learning. Of course any educational innovation carries risks associated with it, especially the reaction of students that have been used to the traditional teaching and learning approaches. This is being addressed by ensuring that the students are aware of the why we take the approaches we take, by establishing a culture of trust and through active personal involvement motivating students intrinsically as they are part of a process and not passive bystanders. 


\section{Embedding Professional Skills through Realistic PBL}

\subsection{Linking Professional Skills to Professional Practice}

After we delivered a number of transferable skills to our Doctoral Training Students during their Diploma in Personal \& Professional Skills, we decided, as we believe that these skills are really learned if they are put into use, that it would make more sense if the students were put in a position that they will have to use these skills under conditions that they will face in an industrial setting. With this in mind we approached a number of SMEs who were prepared to have a go with us and we discussed if they would like to provide small groups of our students with problems that they currently had and they would like solved. Once we formalized the projects we split our 3rd year CDT cohort into 3 groups of 5 - 6 students and these were given minimal information and were sent to their respective SMEs to be told what problem they would have to tackle in the time of two working weeks. The students had access to facilities and resources from both organizations but they had to figure out for themselves what needed to be done, by when, what resources they needed and what resources were available.

At the end of the two weeks the groups would have to present their solution(s) to the groups of their peers, the SMEs and the CDT academics. The result once again was a resounding success on all fronts. The students were totally engaged as they goy immersed in the problems they had to tackle. They quickly found out what needed to be done, who to get in touch with for information, which facilities they needed, where they were and how to access them. Teamwork quickly fell into place with members allocating roles and taking on appropriate responsibilities. Deadlines and managing your time were no longer concepts or statements on Power Point slides but were palpable targets to be met. Networking was put into practice, Motivation, Problem Solving, Project Management, Creativity, Conflict \& Negotiation, Team Building, Communication, Presentation Skills, and each of the other skills that formed the core of the Diploma were used and were assimilated into the students conscience by the experience.

The result were SMEs with current real problems being solved, students that were enthusiastic that they had put their knowledge in good use and learned from what they considered a very valuable exercise and of course the academic staff feeling justified that their flexible approach to learning was paying dividends. But of course it does not stop there, the external examiner will also be happy that the targets we set are being met, industry will benefit in the long run as we will produce the leaders of tomorrow as we envisage.

In bringing together our potential leaders of tomorrow with the industries they might be asked to lead to tackle and solve interdisciplinary real life complex problems is proving to be a coherent and successful way that could be used as a model for students wanting to practice critical, cognitive and professional skills they have acquired through their lives as well as those delivered specifically by the CDT Diploma. Hands-on experience, learning from successful as well as unsuccessful attempts to implement solutions to these problems provides a wealth of opportunities for making the necessary connections between theory and application, academic education and professional practice.

\subsection{Students: Engagement $=$ Motivation}

Learning by doing has a direct motivational effect on students' learning as it is context based on real problems faced by professional practicing engineers and by virtue of "ownership" of the problem felt by the students as they are given minimal supervision by academic staff during the process, students quickly fall back and use the skills they have learned in the various modules of the Diploma as well as those they did not think they have. Students are given responsibility for determining what information they need, responsibility in sorting out the group dynamics, allocation of tasks, project planning and management, time management, facilitation, networking, conflict resolution, negotiation, etc. Suddenly all these abstract topics introduced through the Diploma become valuable resources for seeking information, communication with peers, experts, or gate-keepers, and gathering whatever is necessary to deliver what the customer wants on time. The reality of the problem and professional set-up of the environment they are working over the two weeks brings real meaning to their task and the concepts discussed in class suddenly acquire new meaning helping the students to move beyond the classroom by providing solutions that fulfil real and pressing needs. The groups of students are "forced" by the circumstances, built-in by purpose in the exercise they are asked to undertake, to demonstrate their own personalized problem-solving skills as opposed to having to be told how to solve a problem (which is common practice in the training of engineering students the world over). The process as it develops over the short time scale of 
two weeks is one of engagement, self-directed learning with a meta-cognitive stage where students are asked to reflect, evaluate and refine the skills and strategies they employed in generating their solutions.

When problems are relevant and genuine (not artificially put together, which once again is common practice in the training of engineering students the world over), the levels of comprehension and skill development achieved are a lot higher than what is achieved under traditional instruction [3], in fact some researchers go as far as stating that traditional education methods are not only counterproductive but noticeably hinder natural problem-solving skills, as students are spoon-fed information of how to solve problems rather than been given real problem-solving opportunities [4] [5]. Although artificially conceived, working as part of a group of consultants, they have to continuously switch between working independently and collectively as professionals do all the time. They learn to practice sharing, evaluating, and constructively criticizing each other's work, dealing with multiple and often conflicting goals, ever shifting constraints. To deliver solutions within the constraints set, they quickly become creative, resourceful, accountable, innovative and assertive when they need to be.

\subsection{SMEs: Engagement = Communication}

The best way to demonstrate the engagement of the SMEs with the project is to quote the response of one particular manager:

"We found the process to be both interesting and beneficial. I liked how the students were able to dedicate a short amount of time to such a thorough investigation of the problems we presented them with. I think they accomplished quite a lot in a short time and we found their analysis and conclusions to be very useful.

My only comment would be that although the students were helpful in their analysis of the root cause of the issues and had some recommendations as to what was needed to rectify them. They didn't really suggest what the next steps should be or how they would go about this. For instance, with the group that looked at the CVD die failure; they clearly showed why the die had failed for didn't come up with alternatives we could potentially use which would have been appreciated.

I do understand that given the limited time they had and the fact that the process under investigation was new to them this may have been too much to expect but it's just an observation.

In conclusion, we found the process rewarding and interesting and we were pleased to be able to support the groups.

Kind Regards”

There is continues interaction with the SMEs and through reflection the project is fine-tuned every year. The work of Saras Sarasvathy [6] has been influential in further developing the SME case studies as it neatly correlates with the effectuation approach of the groups of students tackling their particular "real life" projects and this year is intended that a session on effectuation will be introduced in the Diploma workshops prior to the SME cases so that the students become familiar with "effectual reasoning”.

\subsection{Academics: Engagement $=$ Validation}

It is unfortunately quite common that students, even up to doctoral level, have little experience in solving ill-structured, open-ended problems; something that professionals do on a daily basis. Until recently, they had few opportunities to work on integrated multidisciplinary problems; we have been addressing this at the Faculty of Engineering of Sheffield University through week long events such as the Global Engineering Challenge, Skills Week and Engineering: You are hired.

In using real problems generated by SMEs a deliberate link is sought between the Diploma skills content and problem solving as practiced by engineering practitioners in their daily working routines. Research strongly supports the proposition that such approaches result in stronger associations between acquired information (old or new) and skills as well as more personalized knowledge that is memorable and assimilated through the experience and classified accordingly for appropriate future use [7] [8].

A further benefit from the work with the SMEs is that it has allowed us to collect data on the skills used by the students during the process and currently I am analyzing these by plotting them against the skills we believe we are delivering through the CDT Diploma as well as the general skills introduced by the Vitae Researcher Development Framework (RDF) [9]; the results are interesting and will become a publication in an Educational Journal and disseminated through appropriate Conferences. The methodology used in our work is similar to that published by a group at Birmingham University [10] and so far the results from both groups are in general 
agreement.

The work done with the engagement of SMEs resonates well with the sentiment expressed by Anne Marie Morris MP in the recent report by the All-Party parliamentary Group [11] that "without the full engagement of the business community progress in enterprise education cannot be made". She also pointed out that "one of the reasons SMEs don't engage as much as larger business do is that they cannot afford to"; on the other hand, may be the work we are doing shows that SMEs cannot afford not to!

\subsection{Sponsors: Engagement $=$ Validation}

The need to provide UK with the leaders of tomorrow has been outlined by many authors [12] [13] and was addressed by an EPSRC call for the establishment of Centers of Doctoral Training (CDT) across UK. Amongst other successful CDT bids by Sheffield University, The Universities of Sheffield and Manchester together were successful in winning the bid for a CDT in Advanced Metallics. The remit for this 5 year program was that between them the two Universities would deliver $10 \mathrm{PhD}$ level graduates after a four year program. The program was tailored as to have a cohort system, around 18 high caliber students preferably from any scientific or engineering discipline would have a common first year when they would be taught metallurgy related subjects at a masters level in addition to transferable skills, then at the end of year one they would pick their particular theme of research from a variety of project on which they would work for the next 3 years, in parallel with other activities that they would partake in as the original cohort, before qualifying with a PhD. All projects were industry related and the whole structure of the CDT was based on Academia/Industry collaboration. At the start of the CDT experience, the Directors of the Advanced Metallics Group decided on the concept of a Diploma in Personal \& Professional Skills, based on those outlined by the Vitae Researcher Development Framework (RDF) [9], that the cohorts would take through their four years of study so on Graduation the students would leave with a $\mathrm{PhD}$ in a metallurgical field as well as a diploma in skills that are sought after in industry and their need was so well indicated by countless UK and EU publications.

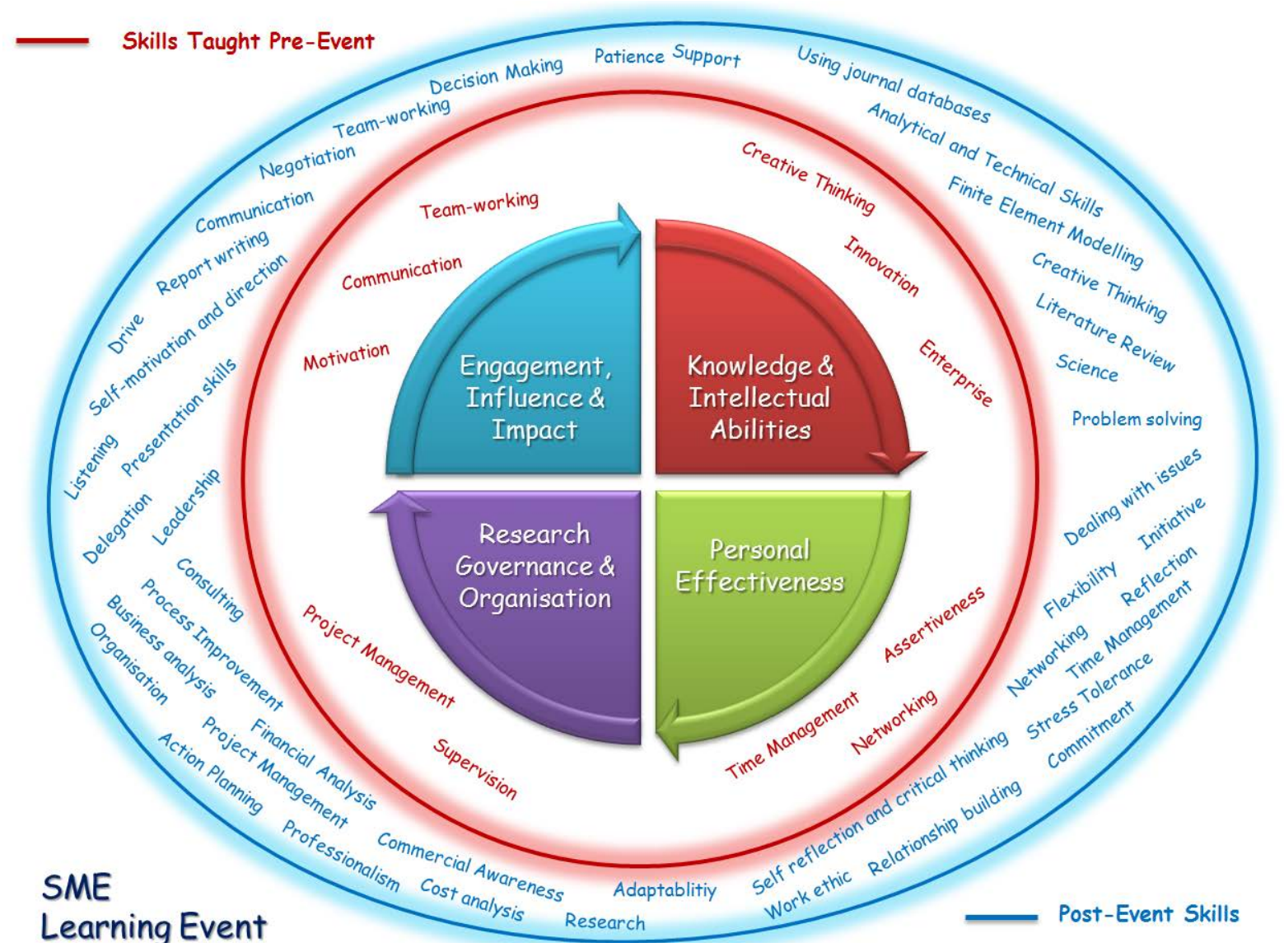


At the completion of the SME projects, students were asked to relate back what skills they had used in working through the two week problem solving exercises. The results were then plotted against the subjects taught through the Diploma and revealed that there is a substantial multiplier effect taking place, providing supportive evidence as shown in the figure above, that not only the skills being taught were used but a wealth of other related skills possessed by individual students surfaced, were used and embedded through to their long term skills armory.

\section{In Conclusion}

The philosophy behind the CDT Diploma in Personal \& Professional Skills and the SME cases in particular, is to cultivate and embed a flexible, integrated, multidisciplinary approach to problem solving in our students rather than approach problem solving as a purely intellectual exercise. We do believe that our educational purpose is to prepare our students for "life" and the realities that they will face. For this, they need instruction and knowledge that is practical, concrete and applicable and for that we profess to deliver education that provokes openness of their minds. My namesake Plato said that "a text is a poor substitute for what really counts, that is the living exchange between different people" and Whitehead concurs with "... there is only one subject matter for education, and that is Life in all its manifestations". This is why our students are put in a position that are confronted with real barriers of deadlines, information, and resources where they have to engage and employ all their technical, social, political and personal skills.

We want to encourage our students to be well rounded professionals with the ambition to create our future wealth and drive our economic growth, ethically and sustainably. We want them to be enterprising and entrepreneurial, full of brilliant useful ideas that are sellable, the game plan changers that will lead us to a better future. We don't want them to predict the future which is nigh impossible, we want them to invent the future which is feasible!

We hope that the enterprising educational approach we have adopted for the CDT Diploma will deliver students with enterprising qualities and skills, knowledge and inventiveness, full of imagination, with the ability to think critically and the courage to think differently. We have been called to create, distil, disseminate and instill these qualities in our students to help in their future careers it's by no means a simple task. In the words of Whitehead [14] "Education is the acquisition of the art of the utilization of knowledge. This is an art very difficult to impart" and remember the best and brightest amongst our students will always find a way to achieve their potential with or without the benefit of a traditional education; most of today's heroes are educational drop-outs!

We are an inquisitive species; we search for answers all the time, even for questions that seemingly are unanswerable. As a youngster I loved the poem Ithaka by Kostas Kavafis as it was in tune with my approach to life: "Travelling in hope is much better than just arriving; it's the whole experience of the travel that counts. That is what life is, a travelling experience, so don't settle on your destination too early; keep on travelling (even virtually)".

I read somewhere in an EU document that "When planning for a year, plant corn; when planning for a decade, plant trees; when for life, train and educate people...” with the CDT Diploma we plan for life, we train and educate people. Finally, in answer to Prof. Dym's question about engineering education [15] "Can we create educational environments in which students learn more about engineering, and with greater interest and enthusiasm?" our answer is "Yes we can"!

\section{Acknowledgements}

The author would like to express his gratitude to USE (University of Sheffield Enterprise Unit for sponsoring his IEEP program attendance, CDT colleagues for their support of this work and last but not least Dr. David Baume for his encouragement and facilitation of continuous improvements that made the CDT Diploma interesting and challenging for all concerned.

\section{Authors and Affiliations}

Dr. Kapranos is a Senior University Teacher at the Department of Materials Science \& Engineering, The University of Sheffield, UK. He is a Fellow of The Higher Education Academy, holds the IEEP Fellowship (International Entrepreneurship Educator Program) and SEDA Accreditation in Leading and Developing Academic Practice (Staff and Educational Development Association Professional Development Framework). 


\section{References}

[1] Jones, C. (2006) Enterprise Education: Revisiting Whitehead to Satisfy Gibbs. Education Training. http://www.academia.edu/2733482/Enterprise education revisiting Whitehead to satisfy Gibbs

[2] Bauman, Z. (2012) On Education: Conversations with Riccardo Mazzeo. Polity Press.

[3] Barrows, H.S. and Bennett, K. (1982) Experimental Studies on the Diagnostic (Problem-Solving) Skill of the Neurologist: Their Implications for Neurological Training. Archives of Neurology, 26, 273-277. http://dx.doi.org/10.1001/archneur.1972.00490090099009

[4] Albanese, M. and Mitchell, S. (1993) Problem-Based Learning: A Review of the Literature on Its Outcomes and Implementation Issues. Academic Medicine, 68, 52-81. http://dx.doi.org/10.1097/00001888-199301000-00012

[5] Johnson, P.A. (1999) Problem-Based Cooperative Learning in the Engineering Classroom. Journal of Professional Issues in Engineering Education and Practice, 125, 8-11. http://dx.doi.org/10.1061/(ASCE)1052-3928(1999)125:1(8)

[6] Sarasvathy, S.D. (2008) What Makes Entrepreneurs Entrepreneurial? http://ssrn.com/abstract=909038

[7] Eisenstaedt, R. (1990) Problem Based Learning: Cognitive Retention and Cohort Traits of Randomly Selected Participants and Decliners. Academic Medicine, 65, 511-512. http://dx.doi.org/10.1097/00001888-199009000-00020

[8] Barrows, H.S. (1991) Cognitive Apprenticeship (Problem-Based Learning). Educacao Medica, 2, 52-81.

[9] Vitae (2009) Research Development Framework. www.vitae.ac.uk/rds

[10] Disney, T., Harrowell, E., Mulhall, R. and Ronayne, M. (2013) Doctoral Researcher Skill Development: Learning through Doing. Planet, 27, 14-20. http://journals.heacademy.ac.uk/doi/full/10.11120/plan.2013.00004 http://dx.doi.org/10.11120/plan.2013.00004

[11] Report (2011) Higher Education: Students at the Heart of the System, Presented to Parliament by the Secretary of State for Business, Innovation and Skills by Command of Her Majesty.

https://www.gov.uk/government/uploads/system/uploads/attachment data/file/31384/11-944-higher-education-students -at-heart-of-system.pdf

[12] Roberts, S.G. (2003) Review of Research Assessment. Oxford. http://www.ra-review.ac.uk/reports/roberts.asp

[13] Dearing, R. (1997) Higher Education in the Learning Society. The National Committee of Enquiry into Higher Education. http://www.educationengland.org.uk/documents/dearing1997/dearing1997.html

[14] Whitehead, A. (1929) The Aims of Education and Other Essays. http://edf.stanford.edu/readings/aims-education-and-other-essays

[15] Dym, C.L. (1999) Learning Engineering: Design, Languages and Experiences. Journal of Engineering Education, 88, 145-148. http://www.2.hmc.edu/ dym/LearningEngrng.pdf http://dx.doi.org/10.1002/j.2168-9830.1999.tb00425.x 